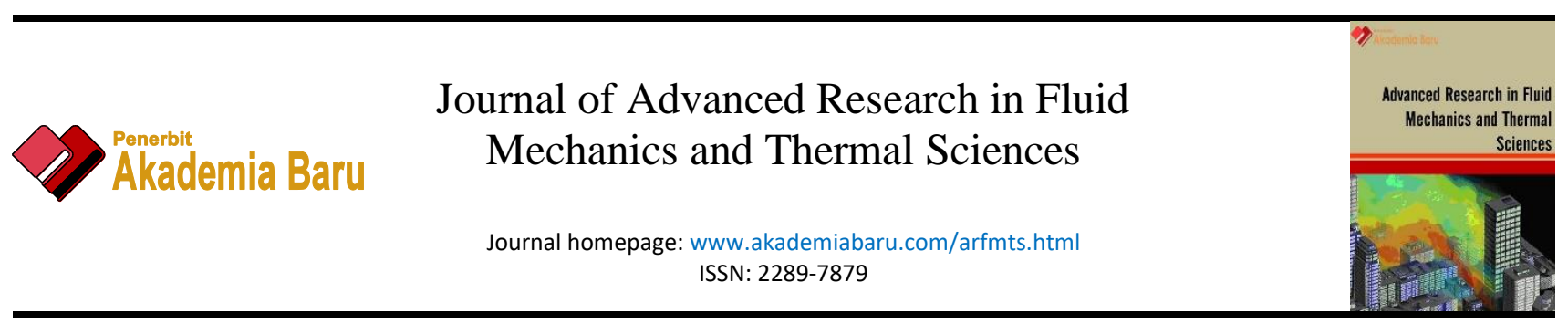

\title{
Flow and Heat Transfer Characteristics of Impinging Bubbly Jet
}

\author{
Chattawat Aroonrujiphan ${ }^{1}$, Chayut Nuntadusit ${ }^{1, *}$ \\ Department of Mechanical Engineering, Faculty of Engineering, Prince of Songkla University, Hat Yai, Songkhla 90110, Thailand
}

Keywords:

Submerged impinging jet; Bubbly jet;

Volumetric fraction; Heat transfer

enhancement

\section{ABSTRACT}

The effect of adding air into water jet flow for heat transfer enhancement was investigated for submerged impinging jet. The Reynolds number of water jet was fixed at $\operatorname{Re}_{\mathrm{L}}=2.4 \times 10^{4}$, the nozzle to impingement surface distance was also fixed at $\mathrm{L}=2 \mathrm{D}$, and the volumetric fraction was varied from $\beta=0.0$ to 0.7 . The heat transfer measurement was studied using an infrared thermal imaging camera. The flow behavior of bubbly jet was observed by a high-speed camera. The result showed that the heat transfer of the bubbly jet for all cases were higher than the water jet case. The average Nusselt number on surface was continuously increased for increasing volumetric fraction $\beta=0.0$ to 0.2 . It was found that the volumetric fraction at $\beta=0.2$ gave the maximum heat transfer enhancement about $33 \%$ compared to case of water jet. But the increase of volumetric fraction in range $\beta=0.2$ to 0.7 decreased the average Nusselt number.

Copyright @ 2020 PENERBIT AKADEMIA BARU - All rights reserved

\section{Introduction}

Jet impingement is widely used in cooling system about thermal equipment or industrial process that operate high temperature because it has high cooling capability in impingement region [1] and it is a rapid cooling system [2]. For example, it has been used for microelectronic components that are operated on extreme temperature condition [3-5], and quenching of steel plates during the manufacturing process that needs to control temperature on materials [6-8]. In the field of electronic cooling, air impinging has been contributed to high heat flux device. Umair et al., [9] studied the effect of pulsating impinging jet on pin fin surface for heat transfer enhancement. They proposed the correlation for predicting heat transfer from pin fin surface to pulsing jet. Siddique et al., [10] also investigated for air impinging jet with consideration to the effect of wall thickness. The uniformity of Nusselt number distribution was studied for different wall target thickness. It was found that

\footnotetext{
* Corresponding author.

E-mail address: chayut.n@psu.ac.th 
impinging air jet cooling becomes more uniform when increasing the target thickness. Due to the development of high heat flux in electronic devices, several researchers have investigated the heat transfer of impinging jet with liquid phase because it can enhance heat transfer rates larger than air or gas phase.

Liquid jet impingement is continuously investigated for heat transfer process due to the high performance of cooling. Commonly, the liquid impinging jet can be divided into 2 types: Free-surface jet and submerged jet as shown in Figure 1 which have a different flow structure. The free-surface impinging jet develops from free jet region to decaying jet region which has no effect shearing between jet flow and surrounding fluid. It causes the velocity of jet flow has almost uniform along a radial direction. The submerged impinging jet develops from free jet region to decaying jet region which has the shearing effect between jet flow and surrounding fluid. It appears shear layer around the jet flow. Therefore, the fluid around the jet flow is accelerated by momentum transfer to surrounding affects to increase mass flow in the jet [11]. Both types of jet flow have impingement region and wall jet region characteristics when its impact on the surface. The free-surface impinging jet is revealed about a phenomenon that is called hydraulic jump, which cannot be found for the submerged impinging. In the past, many researchers have observed for heat transfer characteristics of liquid jet impingement. The important parameters consist of nozzle-to-impingement surface distance (L), Reynolds number (Re), and Prandtl number (Pr). Lv et al., [12] studied heat transfer characteristics of free-surface impinging jet that the effect on impingement distance (L/D) varied from 2 to 5 and Reynolds number in range of 8,000-13,000. The result showed that the maximum heat transfer coefficient was found at $L / D=4$. Nakharintr et al., [13] studied the effect of jet diameter on heat transfer characteristics for impinging jet in a mini-channel heat sink. They showed that the average Nusselt number decreased as the jet diameter decreased because the smaller jet diameter had a smaller stagnation region, which was an important area to high cooling rate on the impingement surface. Sun et al., [14] studied the convection heat transfer rate for submerged impinging jet. The Reynolds number of water jet was varied from 5,000 to 36,000, and jet impingement distance was also varied from 1 to 20 of jet diameter. The result showed that the Nusselt number at stagnation point increased when the Reynolds number of water jet increased. Womac et al., [15] developed the correlation equations for heat transfer of free-surface and submerged liquid impinging jet. Water and fluorocarbon liquid (FC-77) were used for working fluids in both of impinging jet system. They showed that the average Nusselt number on surface for fluorocarbon liquid jet was higher than the water jet.

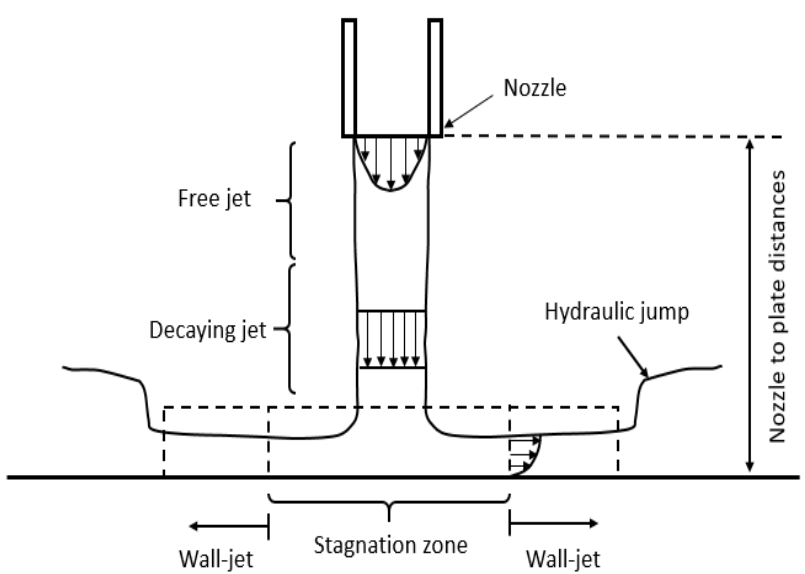

(a) Free-surface jet

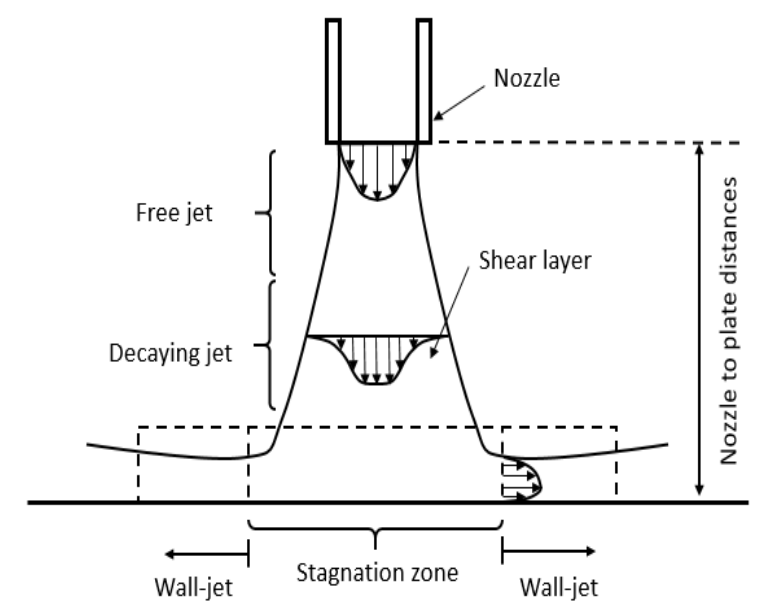

(b) Submerged jet

Fig. 1. Structure of jet impingement 
Improvement of jet impingement cooling system is still important for high heat flux application. Two-phase jet impingement has been investigated recently to enhance heat transfer on the surface which is improved than single-phase jet impingement. For example, nanofluid is widely used for working fluid in impinging jet system. It is a mixture that is between the solid-phase and the liquidphase and it contributes to increasing the thermal conductivity of jet flow. Naphon et al., [16] investigated the heat transfer of impinging jet for $\mathrm{TiO}_{2}$ nanofluids in micro-channel heat sink. The result showed that the convective heat transfer increased by $18.56 \%$ at $0.015 \%$ of volume concentration nanofluid. It could decrease the average temperature of micro-channel heat sink that was by $3.00 \%$ for $0.4 \%$ of nanofluids concentration when compared with single-phase liquid jet impingement [17]. Barewar et al., [18] studied the heat transfer characteristics of impinging jet for ZnO-water nanofluid. Reynolds number of jet was varied from 2,192 to 9,241 and the impingement distance was varied from 2 to 7.5 of jet diameter. The concentration of nanofluid was also varied $0.02 \%, 0.04 \%, 0.06 \%$, and $0.10 \%$ by volume. The experimental result showed that the maximum value of heat transfer coefficient increased by $51 \%, 41.7 \%, 32.9 \%$, and $14.1 \%$ for the concentration at $0.02 \%, 0.04 \%, 0.06 \%$, and $0.10 \%$, respectively. Sun et al., [19] studied the effect of cooling performance of $\mathrm{Cu}$-water nanofluid jet impingement, the volume concentration nanofluid was varied between from $0.1 \%$ to $0.5 \%$. The result showed that the convective heat transfer increased by using Cu-water nanofluids jet for all the volume concentration. Lv et al., [20] studied the heat transfer characteristics of nanofluids impinging jet by using $\mathrm{Al}_{2} \mathrm{O}_{3}$-water. The experimental result showed that the convective heat transfer of $\mathrm{Al}_{2} \mathrm{O}_{3}$-water nanofluids jet increased by 1.17 to 1.64 times of using water jet for the volume concentration nanofluid was varied between $0.5 \%$ to $2 \%$. Although the application of nanofluids contributes to enhancing heat transfer significantly. The main problem may produce the deposition of nanoparticles on impingement plate, which leads to a decrease in heat transfer rate [19].

Instead of applying nanofluid, few researchers have investigated the effect of adding air bubbles into water jet impingement for heat transfer enhancement. Because the jet flow is disturbed by the bubbles that lead to increase turbulence intensity on the impinging jet and some bubbles can disturb the thermal boundary layer on the impingement surface. Choo and Kim [21] studied the effect of adding air bubbles on heat transfer and flow characteristics of free-surface jet impingement for fixed pumping power condition. The volumetric fraction of air was varied from $0 \leq \beta \leq 0.9$. The results showed that the maximum value of Nusselt number was found for volumetric fraction at around $\beta=$ 0.2-0.3 which the flow in pipe nozzle was bubbly flow regime. Trainer et al., [22] studied the heat transfer characteristic of air assistant water for free-surface jet impingement. The Reynolds number of water was between 7,500 $\leq \operatorname{Re}_{L} \leq 15,000$ and Reynolds number of air was between $0 \leq \operatorname{Re}_{G} \leq 5,900$. The results showed that the local Nusselt number at stagnation point increased 2.6 times when compared with the liquid phase only. Friedrich et al., [23] studied the effect of volumetric fraction increment for heat transfer characteristics of air assistant water jet impingement. The results showed that volumetric fraction in range of $\beta=0.1-0.8$ can increase Nusselt number at stagnation point. But the Nusselt number decrease around $\beta=0.8-0.9$ due to the jet flow is largely in the phase of air. Kneer et al., [24] compared the heat transfer rate for submerged and free-surface impinging jets. The result showed that the heat transfer coefficient for submerged jet was higher than the case of freesurface jet. However, the study was limited to a water impinging jet with no air addition.

The purpose of study is to investigate the effect of adding air on flow and heat transfer characteristics of submerged impinging jet. The Reynolds number of water ( $\operatorname{Re}_{\mathrm{L}}$ ) was fixed at $2.4 \times 10^{4}$ and the impingement distance was also fixed at $L=2 D$. The volumetric fraction of air was varied at $\beta$ $=0.0-0.7$. The heat transfer on cooling surface was evaluated using a thermal infrared camera. The flow structure of bubbly jet was also recorded with a high-speed camera. 


\section{Methodology}

\subsection{Experimental Setup}

The experimental model for submerged impinging jet is shown in Figure 2. The jet flow which ejected from the pipe nozzle impinged to the flat surface that had constant heat flux for cooling. The pipe nozzle has an inner diameter at $D=9.5 \mathrm{~mm}$ and $1,000 \mathrm{~mm}$ for length that was ensured fully developed flow at nozzle exit. In this experiment, the distance between nozzle to impingement surface was fixed at $L=2 D$.

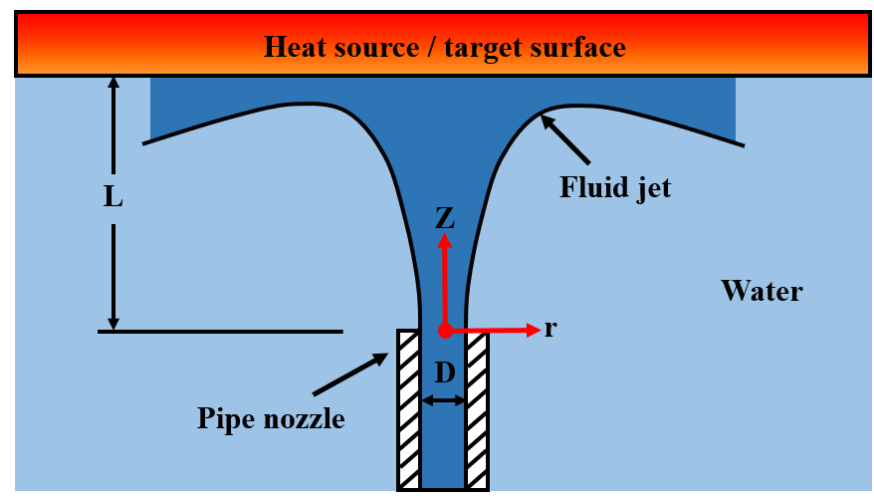

Fig. 2. Impinging jet model for experiment

The diagram of experiment setup is shown in Figure 3. The water was pumped from the reservoir tank by centrifugal pump. And then the water flowed through the temperature control tank to control the water temperature. In the meantime, the air was supplied by air compressor. The flow of water and air were controlled with rotameters. A venturi tube was used as a two-phase mixer between air and water. The temperature of air and water were measured by thermocouples before entering the venturi tube. And then the air mixed water jet flow through the pipe nozzle to the test section. The overflow from test section was connected to the reservoir tank. The water in reservoir tank was cooled with cool water flow via cooling coil. The water temperature including room temperature were also monitored through thermocouples. The temperatures via thermocouples were recorded with data logger during the experiment.

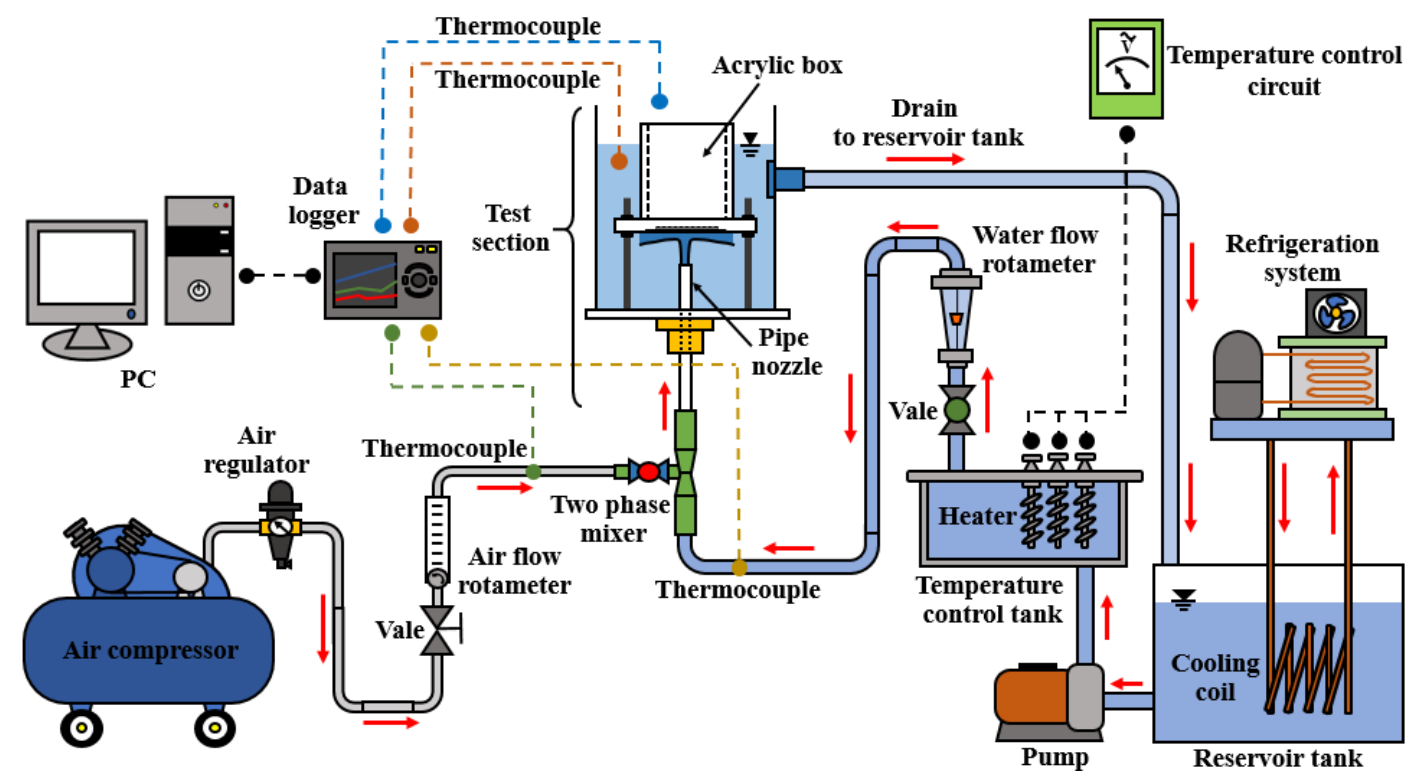

Fig. 3. Schematic diagram of experiment setup 
Figure 4 shows the detail of test section. The test section consists of water tank, pipe nozzle, and impingement plate. The water tank was made of the clear glass plate for sidewall and acrylic plate for the bottom wall. The size of the tank is $30 \mathrm{~cm} \times 30 \mathrm{~cm}$ and $30 \mathrm{~cm}$ for height. There are 4 overflow outlets on each sidewall. The pipe nozzle was made of clear acrylic pipe and inserted from the bottom wall of the tank and fixed with a nozzle adapter. The impingement surface was made of stainless foil SUS304 (100 mm x $100 \mathrm{~mm}$ and $0.03 \mathrm{~mm}$ in thickness) attached on the acrylic plate window with two copper bus bars as shown in Figure 4. Acrylic box was set on the backside of impingement plate for temperature measurement on the rear side of stainless foil using a thermal infrared camera.

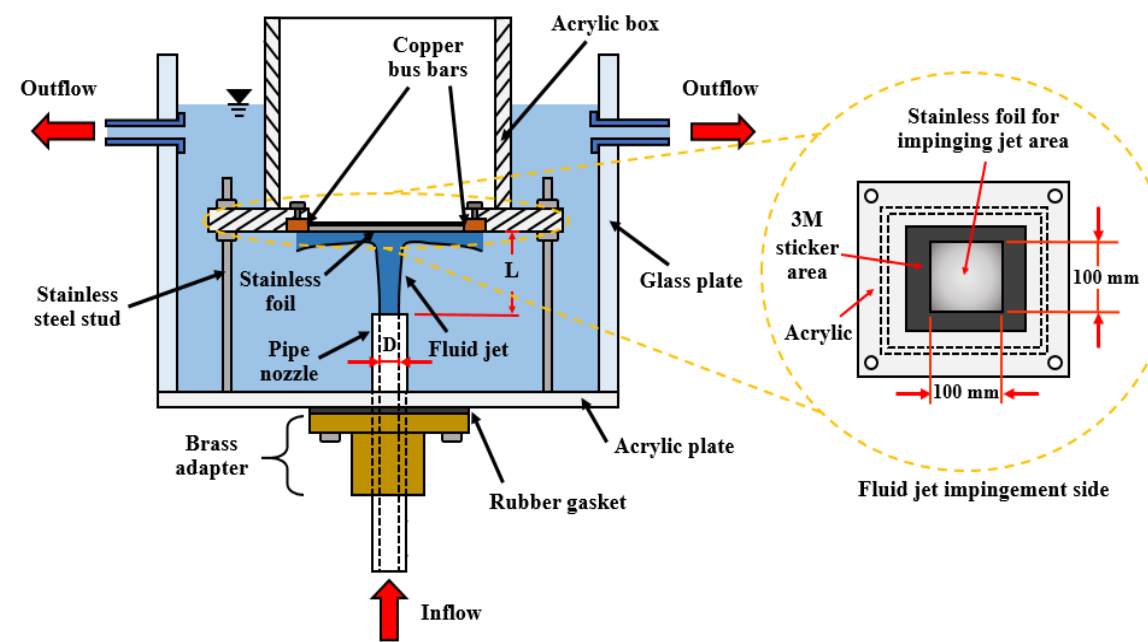

Fig. 4. Detail of test section

\subsection{Experimental Conditions and Parameters}

Experimental parameters are shown in Table 1. The temperature of water flow rate was controlled at $28 \pm 0.1{ }^{\circ} \mathrm{C}$, before it was mixed with the air flow rate. The room temperature was controlled at $25 \pm 0.5^{\circ} \mathrm{C}$. The temperature of air flow was same as water.

Table 1

Experimental parameters

\begin{tabular}{ll}
\hline Parameters and symbol & Values \\
\hline Reynolds number of water, $\operatorname{Re}_{\mathrm{L}}$ & $2.4 \times 10^{4}$ \\
Volumetric fraction, $\beta$ & $0.0 \leq \beta \leq 0.7$ \\
Diameter of jet, $\mathrm{D}$ & $9.5 \mathrm{~mm}$ \\
Nozzle to impingement plate distance, $\mathrm{L}$ & $2 \mathrm{D}$ \\
\hline
\end{tabular}

In this study, the flow rate of water jet was fixed at 9 LPM which is corresponded to Reynolds number at $2.4 \times 10^{4}$. The Reynolds number is calculated from Eq. (1).

$R e_{L}=\frac{\rho_{L} V D}{\mu_{L}}$

where, $\mu_{L}$ is the dynamic viscosity of water. $\rho_{L}$ is density of water. $V$ is the average velocity for water jet. The flow rate of air was varied and correspond to the volumetric fraction as shown in Table 2. And it is calculated from Eq. (2). 
$\beta=\frac{Q_{G}}{Q_{L}+Q_{G}}$

where the water flow rate, $Q_{L}$ was taken as 9 LPM and the air flow rate, $Q_{G}$ were taken as 0 to 21 LPM. Volumetric fraction was varied from 0.0 to 0.7 by increments of 0.1 . This parameter was important for two-phase flow that affect to flow regime of jet flow.

Table 2

The volumetric fraction of jet flow

\begin{tabular}{lll}
\hline$\beta$ & $Q_{L}$ (LPM) & $Q_{G}$ (LPM) \\
\hline 0.0 & 9 & 0 \\
0.1 & 9 & 1 \\
0.2 & 9 & 2.25 \\
0.3 & 9 & 3.86 \\
0.4 & 9 & 6 \\
0.5 & 9 & 9 \\
0.6 & 9 & 13.5 \\
0.7 & 9 & 21 \\
\hline
\end{tabular}

\subsection{Flow Visualization and Heat Transfer Measurement}

Experimental setup for flow visualization is shown in Figure 5. the pipe nozzle and water tank wall were made of a clear material. The high-speed camera was used to record the water-air flow in pipe nozzle and water-air jet flow from nozzle to impingement plate.

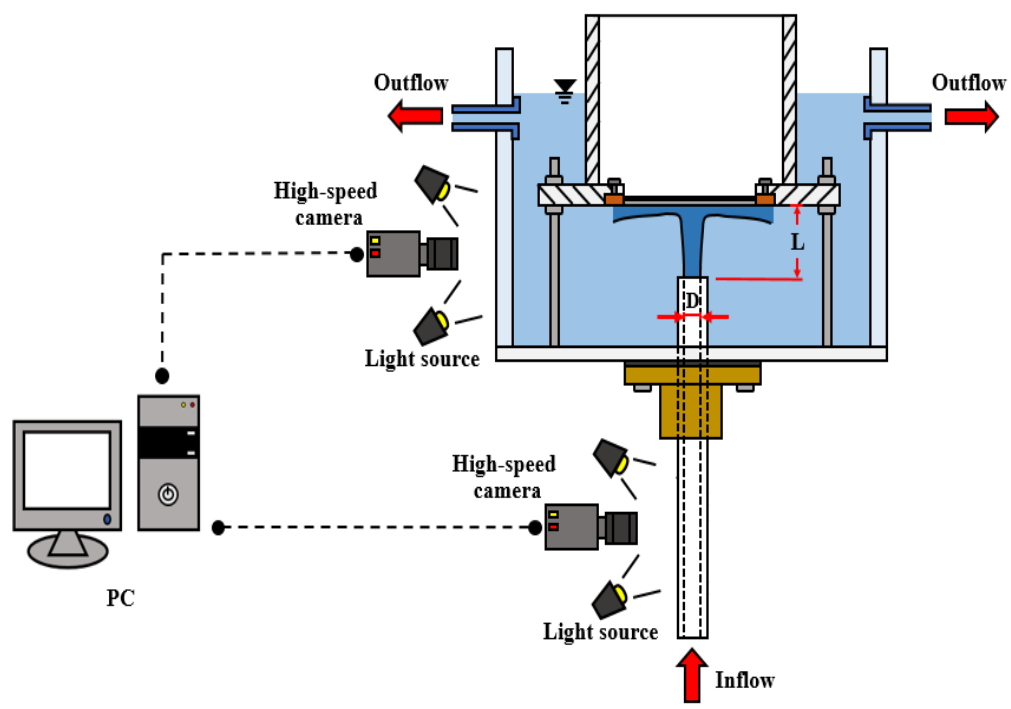

Fig. 5. Experimental setup for flow visualization

Experimental setup for heat transfer measurement is shown in Figure 6 . The infrared thermal imaging camera was used to measured temperature distribution on the rear side of the stainless foil. The measured surface was painted with black spray had emissivity at 0.95 . The stainless foil was then heated by constant heat flux condition with electrical current from DC power supply via the copper bus bars. The heat was generated by resistance of stainless foil with Joule effect. The digital power meter was used to measure voltage drop and current through the copper bus bars. 


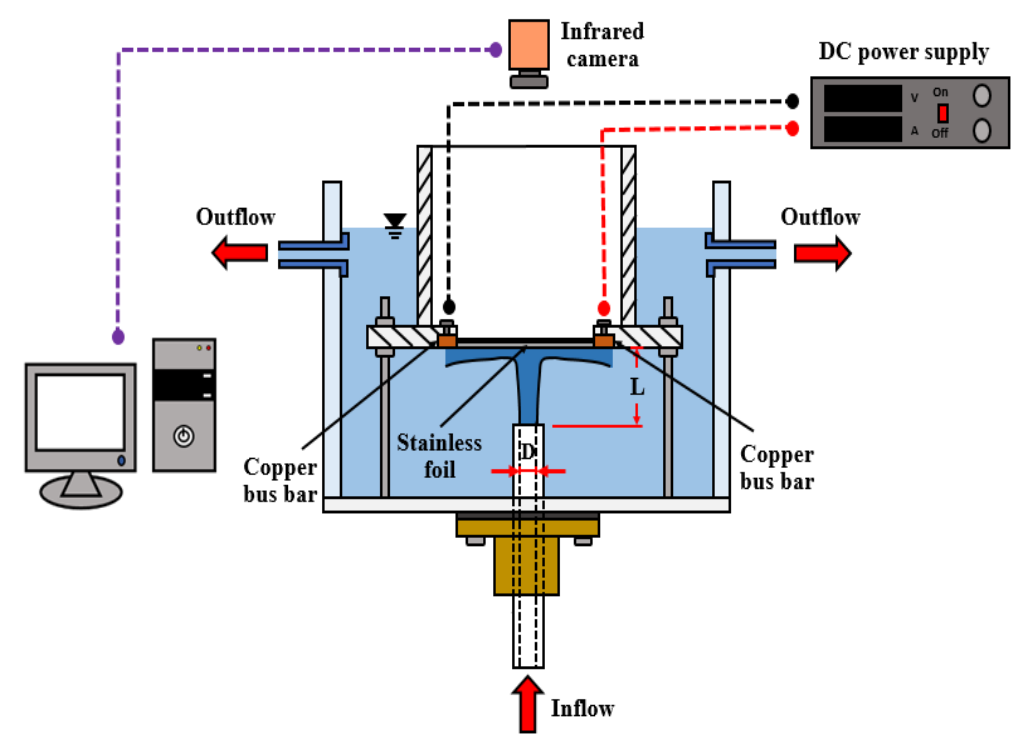

Fig. 6. Experimental setup for study of heat transfer measurement

For heat transfer calculation, input heat flux to stainless surface was

$\dot{q}_{\text {input }}=\frac{I V}{A}$

The heat loss due to radiation and natural convection from rear side of the stainless foil to surrounding were

$\dot{q}_{\text {rad }}=\sigma \varepsilon\left(\bar{T}_{w}^{4}-\bar{T}_{\text {sur }}^{4}\right)$

$\dot{q}_{\text {conv }}=h_{c}\left(\bar{T}_{w}-\bar{T}_{\text {sur }}\right)$

And the net heat flux from the impingement surface to the jet flow was

$\dot{q}_{\text {net }}=\dot{q}_{\text {input }}-\dot{q}_{\text {rad }}-\dot{q}_{\text {conv }}$

(6)

The heat transfer coefficient was calculated with

$h=\frac{\dot{q}_{n e t}}{\left(\bar{T}_{w}-\bar{T}_{a w}\right)}$

(7)

where $I, V$ and A were current, voltage of electric power and area of heat transfer surface, respectively. $\sigma$ was the Stefan-Boltzmann constant $\left(5.67 \times 10^{-8} \mathrm{~W} / \mathrm{m}^{2} \mathrm{~K}^{4}\right)$. $\varepsilon$ was the emissivity of black surface (0.95). $\bar{T}_{w}$ was the time average temperature on a surface with heat flux and $\bar{T}_{a w}$ was the time average temperature on a surface without heat flux. These values were averaged from 500 images taken from the infrared camera every 1 image/second. This is due to the impingement of bubbles in water jet flow affect to change of the temperature on the surface. $\bar{T}_{\text {sur }}$ was the average room temperature during the experiment which was recorded by the data logger and $h_{c}$ was the heat transfer coefficient for natural convection for heated horizontal plate. 
Finally, the Nusselt number was calculated from

$$
N u=\frac{h D}{\mathrm{k}}
$$

where $\mathrm{k}$ was the conductivity of the water.

\section{Results}

\subsection{The Flow Visualization for In Pipe Nozzle and Impinging Jet}

Figure 7 shows the flow visualization results in the middle part of pipe nozzle at different volumetric fractions. The high-speed camera was used to capture at $6400 \mathrm{fps}$. However, the instantaneous flow pattern was shown in Figure 7. The air bubbles increase according to the increase of the volumetric fractions. The results of flow patterns in pipe were divided into 3 cases. For case of $\beta=0.1$, it was in bubbly flow regime which having some small air bubbles distributed in flow pipe. For case of $0.2 \leq \beta \leq 0.3$, it was slug flow regime that the small air bubbles merge to larger a bubble and the shape of air bubble like the bullet shape. For case of $0.4 \leq \beta \leq 0.7$, it was in annular flow regime that the slug bubbles merge together and the middle area of pipe was mostly covered by gas phase. the liquid phase with small air bubbles was on the pipe wall.

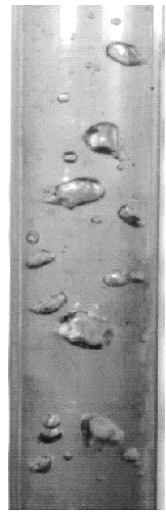

$\beta=0.1$

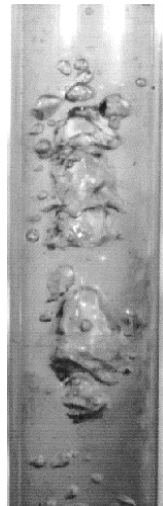

$\beta=0.2$

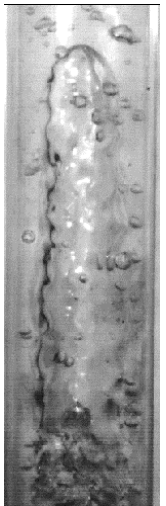

$\beta=0.3$

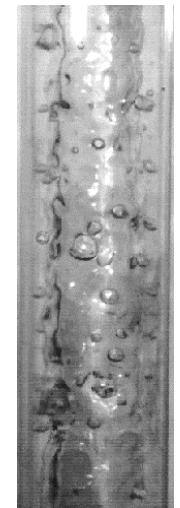

$\beta=0.4$

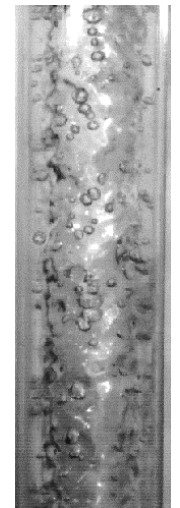

$\beta=0.5$

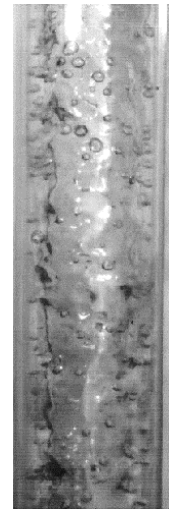

$\beta=0.6$

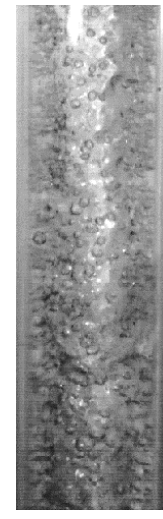

$\beta=0.7$

Fig. 7. Flow visualization in pipe nozzle at different volumetric fractions

Figure 8 shows the flow visualization of impinging jet for different volumetric fractions. Each case shows the instantaneous flow at 3 timings: $t, t+75 \mathrm{~ms}$ and $t+150 \mathrm{~ms}$. Results of flow patterns of impinging jet can be divided into 4 patterns. For case of $\beta=0.1$, the jet flow was similar to the bubbly regime in pipe nozzle and impinged on the impingement surface.

For case of $\beta=0.2$ and 0.3 , the bubble in jet flow was like bullet shape. The air bubble interacted with the surrounding of water and the cloud of bubbles changed to mushroom shape. This cloud of bubbles impinged on the surface cover a large area in impingement region. This can promote the heat transfer than case of $\beta=0.1$.

For case of $\beta=0.4$ and 0.5 , the bubble cloud appears near the pipe nozzle and moved to impinge on the surface. The mushroom shape of the bubble cloud becomes larger with the increase of volumetric fraction. The cloud of bubble covers a large area on impingement surface. This trend is the same for case of $\beta=0.6$ and 0.7 . However, the bubble cloud expands from the nozzle exit to the impingement surface. 

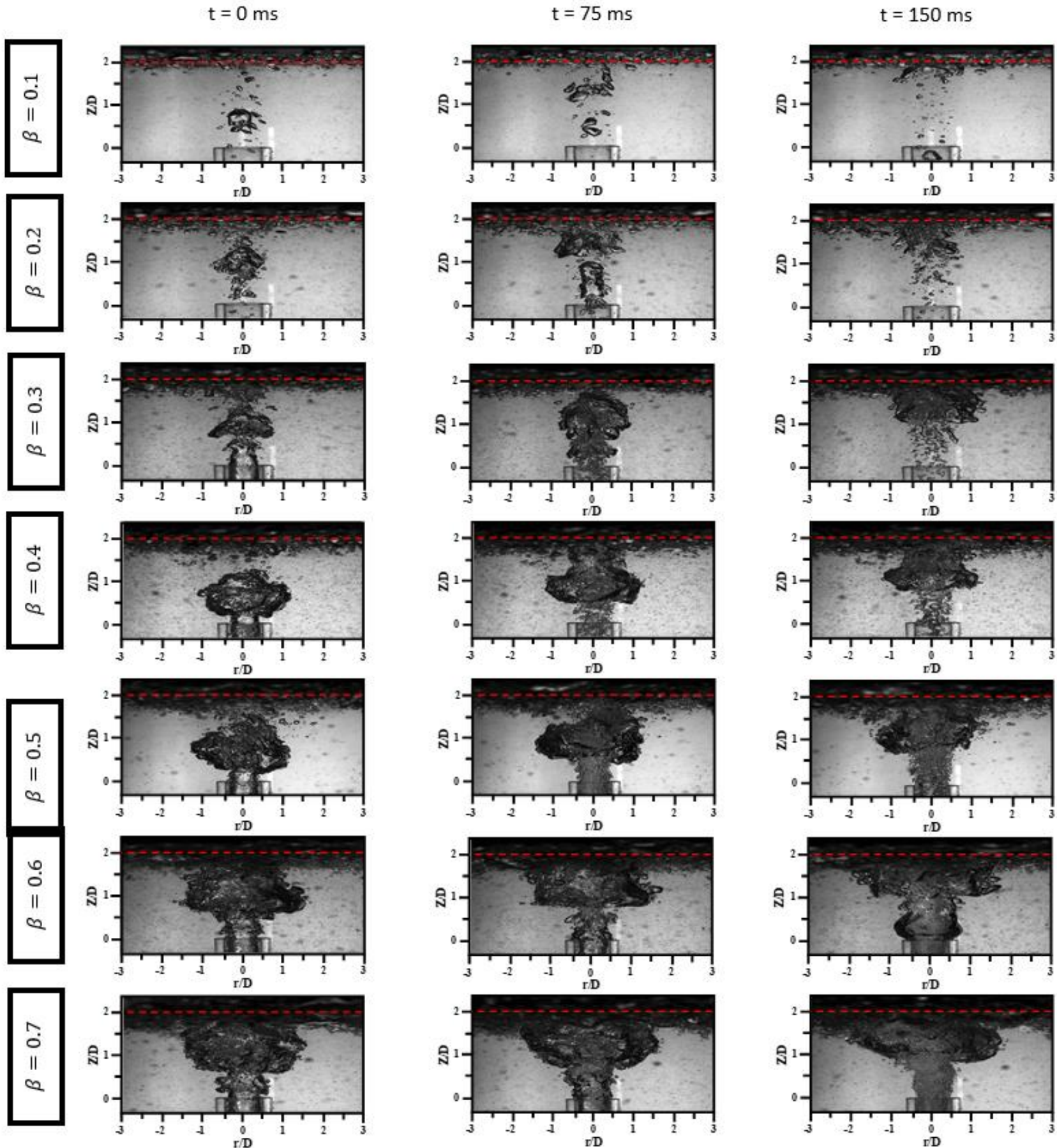

Fig. 8. Flow visualization of impinging jet at different volumetric fractions

\subsection{Heat Transfer Characteristics}

Figure 9 shows the contour of time-average Nusselt number distribution. The volumetric fractions were varied from 0.0 to 0.7 at nozzle to impingement plate distances of $L=2 D$ and Reynolds number of water of $\operatorname{Re}_{\mathrm{L}}=2.4 \times 10^{4}$. For case of $\beta=0.0$, the local Nusselt number is lowest when compared to the other cases. When adding the airflow into the water jet flow, the local Nusselt number in impingement region and wall jet region increase significantly. Particularly, the case of $\beta=0.2$ gives the maximum Nusselt number in impingement region. This is due to the mushroom shape of cloud bubbles impinged on the surface. And the air bubbles disturb the thermal boundary on impingement 
surface. However, the Nusselt number tends to decrease when the increase of volumetric fraction is more than 0.2. This is due to the large cloud bubbles impact the surface.

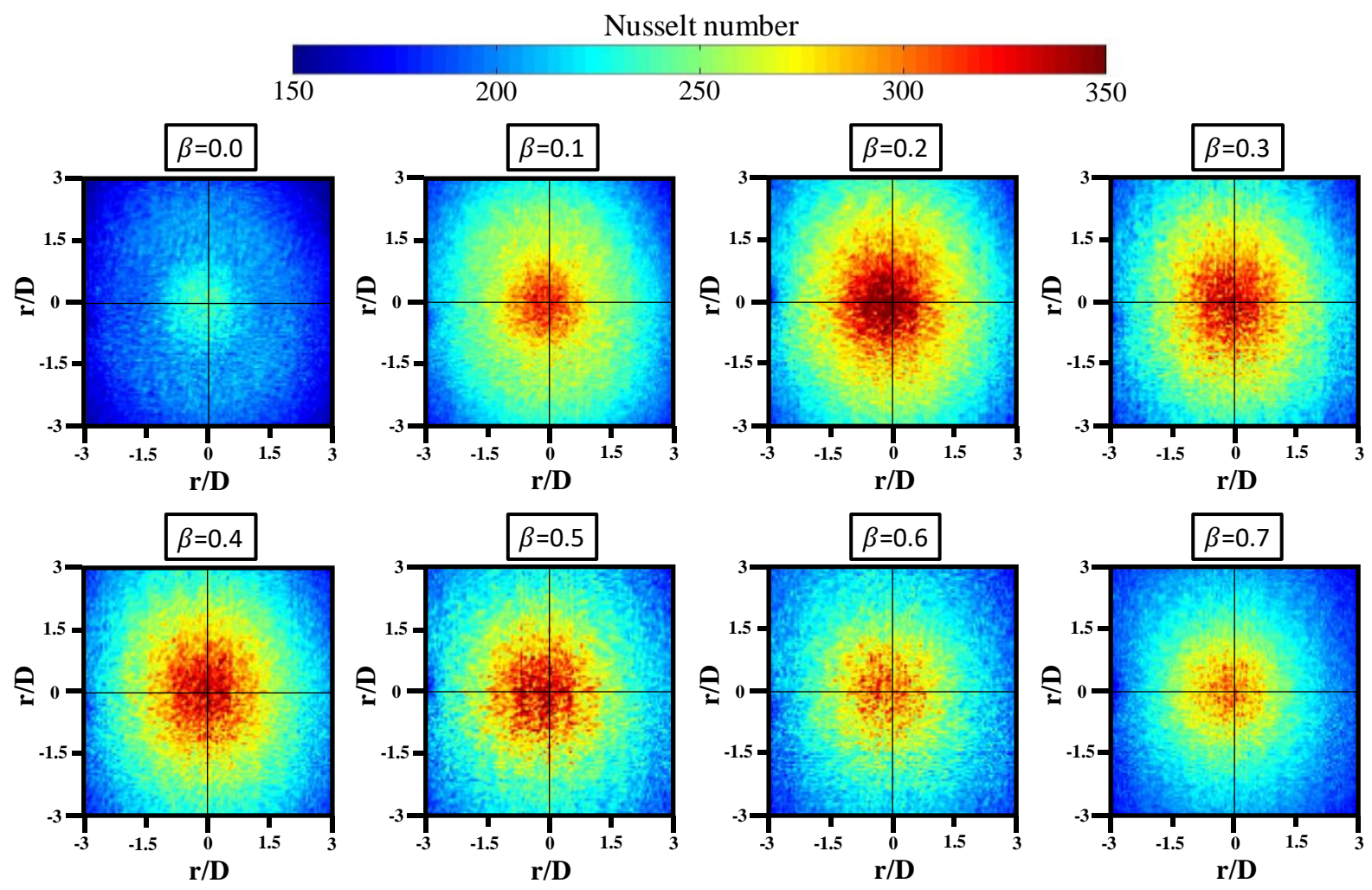

Fig. 9. Contour of time-average Nusselt number distribution at different volumetric fractions for $L=$ $2 \mathrm{D}$ and $\mathrm{Re}_{\mathrm{L}}=24,000$

Figure 10 shows local Nusselt number distribution along $r$-axis at different volumetric fractions. The Nusselt number becomes maximum at the $r / D=0$ and decreases gradually as going far from the downstream. It is cleared that the air bubbles can promote the heat transfer overall the impingement surface. The volumetric fraction has an effect on the heat transfer enhancement. The volumetric fraction, $\beta=0.2$ gives the maximum Nusselt number.

To compare the heat transfer enhancement, the average Nusselt number in area of $-3 D \leq r \leq 3 D$ was compared between impinging bubbly jet $(\overline{N u})$ and impinging jet for case of $\beta=0.0\left(\overline{N u}_{0}\right)$ as average Nusselt number ratio $\left(\overline{N u} / \overline{N u}_{0}\right)$ shown in Table 3. It was found that case of $\beta=0.2$ gives the maximum heat transfer enhancement about 33\%. The other cases of volumetric fraction give the heat transfer enhancement in range of $15 \%-28 \%$. 


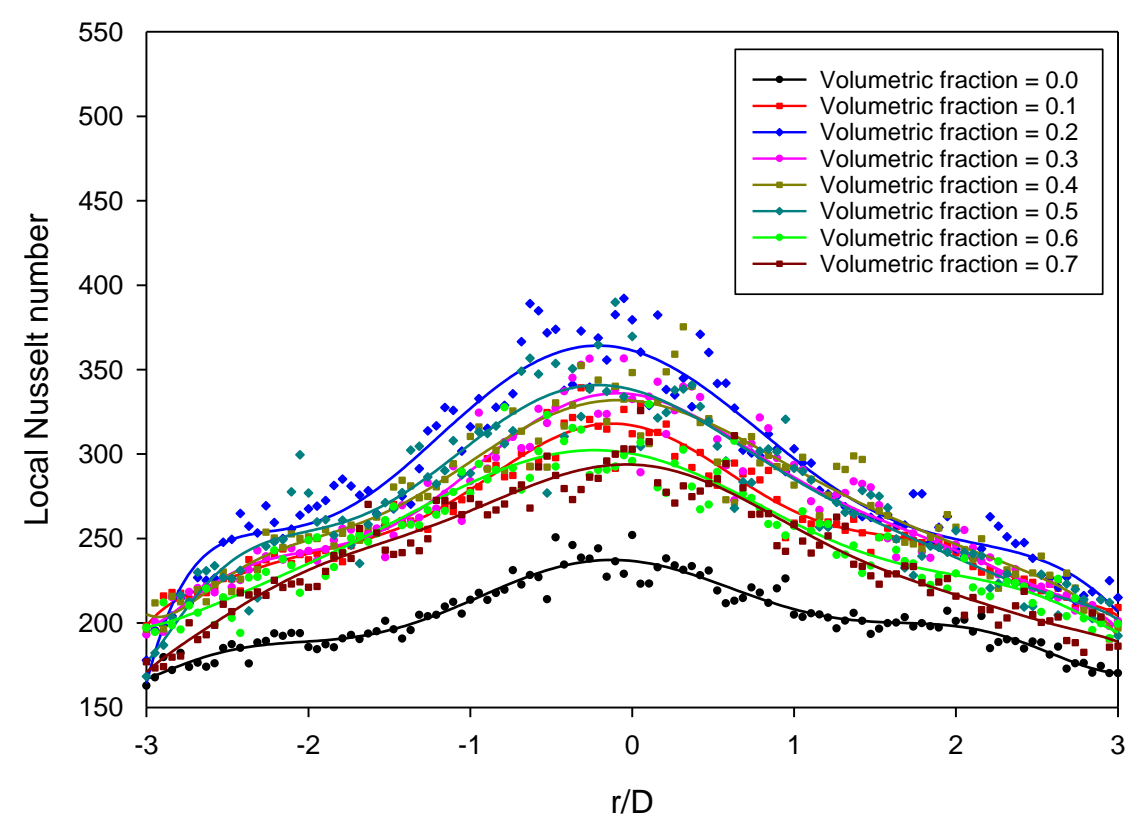

Fig. 10. Local Nusselt number distribution along $r$-axis at different volumetric fractions

\section{Table 3}

Average Nusselt number ratio between bubbly jet and water jet $(\beta=0.0)$

\begin{tabular}{ll}
\hline Volumetric fraction, $\beta$ & $\overline{N u} / \overline{N u}_{0}$ \\
\hline 0.1 & 1.24 \\
0.2 & 1.33 \\
0.3 & 1.28 \\
0.4 & 1.27 \\
0.5 & 1.25 \\
0.6 & 1.19 \\
0.7 & 1.15 \\
\hline
\end{tabular}

\section{Conclusions}

In the present, this research for the heat transfer enhancement and flow visualization of bubbly jet impingement were investigated under fixed Reynolds number of water $\left(\operatorname{Re}_{\mathrm{L}}=2.4 \times 10^{4}\right)$ and nozzle to impingement plate distance $(L=2 D)$, the volumetric fraction was varied from 0.0 to 0.7 . It can be summarized as follow:

i. Heat transfer enhancement by adding air into water impinging jet for all volumetric fractions are higher than a case of pure water impinging jet.

ii. For $\beta=0.1$ to 0.2 , it was found that the average Nusselt number is continuously increased and volumetric fraction at $\beta=0.2$ gives the maximum average Nusselt number about $33 \%$. The jet flow pattern forms the cloud bubble with a mushroom shape that is interacted with the surrounding water. It presents proper air quantity that occurs to disturb the thermal boundary layer on the impingement surface and increases turbulence intensity on jet flow.

iii. For $\beta=0.2$ to 0.7 , it was found that the average Nusselt number is continuously decreased. The jet flow pattern is also found that the cloud bubble with mushroom shape that rapidly expanded when the volumetric fraction increases. It leads to the cloud of bubble covers a large region on the impingement surface which decreases the heat transfer. 


\section{Acknowledgement}

This research was funded by a grant from Department of Mechanical Engineering, Faculty of Engineering, Prince of Songkla University, Thailand.

\section{References}

[1] Wae-hayee, Makatar, Kirttayoth Yeranee, Ibroheng Piya, Yu Rao, and Chayut Nuntadusit. "Heat transfer correlation of impinging jet array from pipe nozzle under fully developed flow." Applied Thermal Engineering 154 (2019): $37-$ 45.

https://doi.org/10.1016/i.applthermaleng.2019.03.044

[2] Nuntadusit, C., M. Wae-hayee, and N. Kaewchoothong. "Heat transfer enhancement on a surface of impinging jet by increasing entrainment using air-augmented duct." International Journal of Heat and Mass Transfer 127 (2018): 751-767. https://doi.org/10.1016/j.ijheatmasstransfer.2018.06.130

[3] Sabato, Massimo, Andrea Fregni, Enrico Stalio, Federico Brusiani, Maurizio Tranchero, and Thierry Baritaud. "Numerical study of submerged impinging jets for power electronics cooling." International Journal of Heat and Mass Transfer 141 (2019): 707-718. https://doi.org/10.1016/i.ijheatmasstransfer.2019.06.081

[4] de Oliveira, Pablo A., and Jader R. Barbosa Jr. "Novel two-phase jet impingement heat sink for active cooling of electronic devices." Applied Thermal Engineering 112 (2017): 952-964. https://doi.org/10.1016/i.applthermaleng.2016.10.133

[5] Masip, Yunesky, Antonio Campo, and Suleivys M. Nunez. "Experimental analysis of the thermal performance on electronic cooling by a combination of cross-flow and an impinging air jet." Applied Thermal Engineering 167 (2020): 114779. https://doi.org/10.1016/i.applthermaleng.2019.114779

[6] Lee, Jaewon, Gihun Son, and Han Young Yoon. "Numerical simulation of the quenching process in liquid jet impingement." International Communications in Heat and Mass Transfer 61 (2015): 146-152. https://doi.org/10.1016/j.icheatmasstransfer.2014.12.017

[7] Waldeck, Steffen, Hermann Woche, Eckehard Specht, and Udo Fritsching. "Evaluation of heat transfer in quenching processes with impinging liquid jets." International Journal of Thermal Sciences 134 (2018): 160-167. https://doi.org/10.1016/j.ijthermalsci.2018.08.001

[8] Karwa, Nitin, Lukas Schmidt, and Peter Stephan. "Hydrodynamics of quenching with impinging free-surface jet." International Journal of Heat and Mass Transfer 55, no. 13-14 (2012): 3677-3685. https://doi.org/10.1016/j.ijheatmasstransfer.2012.02.035

[9] Umair, Siddique Mohd, Sher Afghan Khan, Abdulrahman Alrobaian, and Emaad Ansari. "Numerical study of heat transfer augmentation using pulse jet impinging on pin fin heat sink." CFD Letters 11 (2018): 84-91.

[10] Siddique, Umair, Emaad Ansari, Sher Afghan Khan, and Rajesh Patil. "On Numerical Investigation of Nusselt Distribution Profile of Heat Sink Using Lateral Impingement of Air Jet." CFD Letters 11, no. 9 (2019): 59-68.

[11] Bieber, Malte, Reinhold Kneer, and Wilko Rohlfs. "Self-similarity of heat transfer characteristics in laminar submerged and free-surface slot jet impingement." International Journal of Heat and Mass Transfer 104 (2017): 1341-1352. https://doi.org/10.1016/i.ijheatmasstransfer.2016.08.104

[12] Lv, Jizu, Chengzhi Hu, Minli Bai, Ke Zeng, Shengnan Chang, and Dongdong Gao. "Experimental investigation of free single jet impingement using SiO2-water nanofluid." Experimental Thermal and Fluid Science 84 (2017): 39-46. https://doi.org/10.1016/i.expthermflusci.2017.01.010

[13] Nakharintr, Lursukd, Paisarn Naphon, and Songkran Wiriyasart. "Effect of jet-plate spacing to jet diameter ratios on nanofluids heat transfer in a mini-channel heat sink." International Journal of Heat and Mass Transfer 116 (2018): 352-361. https://doi.org/10.1016/j.ijheatmasstransfer.2017.09.037

[14] Sun, H., C. F. Ma, and W. Nakayama. "Local characteristics of convective heat transfer from simulated microelectronic chips to impinging submerged round water jets." Journal of Electronic Packaging 115 (1993): 71 77. https://doi.org/10.1115/1.2909304

[15] Womac, D. J., S. Ramadhyani, and F. P. Incropera. "Correlating equations for impingement cooling of small heat sources with single circular liquid jets." Journal of Heat Transfer 115, no. 1 (1993): 106-115. https://doi.org/10.1115/1.2910635 
[16] Naphon, Paisarn, and Somchai Wongwises. "Experimental Study of Jet Nanofluids Impingement System for Cooling Computer Processing Unit." Journal of Electronics Cooling and Thermal Control 1 (2011): 38-44. https://doi.org/10.4236/jectc.2011.13005

[17] Naphon, P., L. Nakharintr, and S. Wiriyasart. "Continuous nanofluids jet impingement heat transfer and flow in a micro-channel heat sink." International Journal of Heat and Mass Transfer 126 (2018): 924-932. https://doi.org/10.1016/i.ijheatmasstransfer.2018.05.101

[18] Barewar, Surendra D., Shravan Tawri, and Sandesh S. Chougule. "Heat transfer characteristics of free nanofluid impinging jet on flat surface with different jet to plate distance: An experimental investigation." Chemical Engineering and Processing-Process Intensification 136 (2019): 1-10.

https://doi.org/10.1016/i.cep.2018.12.001

[19] Sun, Bin, Yi Qu, and Di Yang. "Heat transfer of single impinging jet with Cu nanofluids." Applied Thermal Engineering 102 (2016): 701-707. https://doi.org/10.1016/j.applthermaleng.2016.03.166

[20] Lv, Jizu, Shengnan Chang, Chengzhi Hu, Minli Bai, Peng Wang, and Ke Zeng. "Experimental investigation of free single jet impingement using Al203-water nanofluid." International Communications in Heat and Mass Transfer 88 (2017): 126-135. https://doi.org/10.1016/j.icheatmasstransfer.2017.08.017

[21] Choo, Kyosung, and Sung Jin Kim. "Heat transfer and fluid flow characteristics of two-phase impinging jets." International Journal of Heat and Mass Transfer 53, no. 25-26 (2010): 5692-5699. https://doi.org/10.1016/i.ijheatmasstransfer.2010.08.013

[22] Trainer, Daniel, Jungho Kim, and Sung Jin Kim. "Heat transfer and flow characteristics of air-assisted impinging water jets." International Journal of Heat and Mass Transfer 64 (2013): 501-513. https://doi.org/10.1016/i.ijheatmasstransfer.2013.04.048

[23] Friedrich, Brian K., Tamira D. Ford, Aspen W. Glaspell, and Kyosung Choo. "Experimental study of the hydrodynamic and heat transfer of air-assistant circular water jet impinging a flat circular disk." International Journal of Heat and Mass Transfer 106 (2017): 804-809. https://doi.org/10.1016/i.ijheatmasstransfer.2016.09.102

[24] Kneer, Reinhold, Herman Haustein, Claas Ehrenpreis, and Wilko Rohlfs. "Flow structures and heat transfer in submerged and free laminar jets." In International Heat Transfer Conference Digital Library. Begel House Inc., 2014. https://doi.org/10.1615/lHTC15.kn.000028 